LA CLEMENCIA VINCULADA POR EL DERECHO

CÉSAR AGUADO RENEDO 
11_Aguado 7/5/09 09:58 Página 334

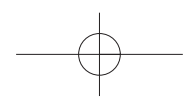

SUMARIO

I. MEDIDAS DE CLEMENCIA Y CONSTITUCIÓN. II. LA GRACIA. III. LA AMNISTÍA. IV. PRESCRIPCIÓN. 


\title{
LA CLEMENCIA VINCULADA POR EL DERECHO
}

\author{
POR \\ CÉSAR AGUADO RENEDO \\ Profesor Titular de Derecho Constitucional \\ (Universidad Autónoma de Madrid)
}

\section{MEDIDAS DE CLEMENCIA Y CONSTITUCIÓN *}

La Constitución española no contiene alusión alguna, directa o indirecta, a la prescripción, ni en materia penal ni en ninguna otra, pero sí contiene en cambio alusiones especificas a la gracia en su versión concreta del indulto, de donde se deduce, por interpretación, el régimen de la amnistía, que tampoco es específicamente aludida. Esto evidencia de inmediato la ambigüedad de la amnistía, aumentada por la ausencia de una doctrina jurisprudencial constitucional específica en materia de amnistía o, más en general, de gracia. Ciertamente se encuentran en dicha doctrina algunas referencias sobre todo respecto de los efectos (económicos, laborales, etc.) derivados de las leyes, y más generalmente, de las normas de amnistía adoptadas durante la transición política del régimen del General Franco al régimen democrático actual. Pero, en rigor, no parece que las

\footnotetext{
* Se ofrece a continuación la traducción del rapport español presentado por quien suscribe en la Journée d'études de "Les institutions de Clemence: Regards de Droit comparé», organizado por la UMR de Droit comparé de París avec la soutien de la Mission de Recherche Droit et Justice, en la Université Paris 1-Pantheón-Sorbonne, a finales de septiembre de 2005. La reunión se encuadraba en el proyecto Recherche Amnistie, Grâce, Prescription en Europe, subvencionado por la Mission Recherche Droit et Justice du Ministère de la Justice (GIP), proyecto que constó de dos secciones, por expresarlo así: una de Derecho Internacional y otra de Derecho Constitucional, perteneciendo la aportación que sigue, evidentemente, a esta última. El resultado del proyecto ha aparecido en for-
}

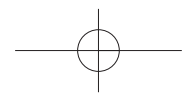


mismas puedan ser consideradas como conformadoras de una doctrina específica sobre la materia de la que quepa deducir las «grandes líneas» al respecto por las inquiere el cuestionario.

La Constitución española contiene tres referencias a la gracia, entendida en sentido general, en estrecha relación con lo que en otros sistemas se designa como clemencia y perdón. Esas tres referencias son las siguientes:

una atribución al Rey del ejercicio del derecho de gracia con arreglo a la ley, impidiéndose la autorización de indultos generales [art. 62.i)]

una prohibición a la iniciativa legislativa popular en lo relativo a la prerrogativa de gracia (art. 87.3)

una prohibición de la aplicación de la prerrogativa real de gracia al Presidente y a los demás miembros del Gobierno, con motivo de su responsabilidad criminal declarada (art. 102.3).

El hecho de que el indulto general esté prohibido por la Constitución, que sólo hace referencia a la gracia individual, ha llevado a una parte de la doctrina, conforme al argumento a minori ad maius, a entender que la amnistía es una institución inexistente en el ordenamiento español actual. Sin embargo, pese a que efectivamente no haya habido amnistías después de la Constitución de 1978 (las últimas fueron las antes aludidas habidas en el período de la transición política), en abstracto nada parece impedir que el legislador, en uso de su libertad de configuración, pueda amnistiar si lo juzga oportuno; sólo él podría hacerlo, ciertamente, dada la diferente naturaleza de la amnistía respecto del indulto, pues mientras éste se proyecta sobre las penas, la amnistía lo hace sobre el acto ilícito, operando sobre él como si nunca hubiere existido, con posibilidad

ma de un grueso volumen bajo el título La Clémence saisie par le Droit. Amnistie, prescription et grâce en Droit International et Comparé, sous la direction de H. Ruiz Fabri, G. Della Morte, E. Lambert Abdelgawad et K. Martin-Chenut, Société de Législation Comparée, Paris, 2007, del que la presente aportación ocupa las páginas 393 a 405. Lo publicado es una reformulación definitiva, llevada a cabo por algunos de los miembros del proyecto, de las respuestas a un cuestionario relativamente detallado, distribuido en su momento entre los encargados de dar cuenta del estado de la cuestión en los distintos sistemas jurídicos analizados: la presente exposición respeta el formato tal y como ha aparecido y, a salvo de lo que se dirá inmediatamente, la literalidad de la reformulación aludida. El principal motivo del ofrecimiento de la traducción del rapport a la Revista de Derecho Político, es que su autor siempre ha considerado una cortesía académica necesaria para los posibles interesados en un determinado tema, facilitar en el propio idioma las publicaciones en otras lenguas, incluso cuando se trata de una lengua más asequible que otras, como sucede en el presente caso. $\mathrm{Si}$, además, algunas expresiones y algunos términos que los redactores definitivos de la publicación han utilizado no se cohonestan del todo con el original aportado, si se hace algún añadido y si el volumen editado, de notable interés sin duda, no parece de fácil acceso por la distribución de la editorial u otras razones, el ofrecimiento resulta si cabe más útil. 
de efectos incluso retroactivos sobre las penas ya purgadas (con resultados como la restitución de multas, cobro de salarios que se hayan dejado de percibir, indemnizaciones o rehabilitación del nombre o del honor): de hecho, como se verá más adelante, cabe detectar ciertas regulaciones en el ordenamiento español vigente que difícilmente no podrían ser calificadas de amnistía.

Por lo demás, el ordenamiento español conoce disposiciones sobre la rehabilitación, entendiendo por ellas las destinadas a moderar la ejecución estricta de la pena, y permitiendo bien el mantenimiento del condenado en la sociedad (caso, por ejemplo, de la suspensión de ejecución de penas o la sustitución de penas leves de privación de libertad por trabajos en favor de la comunidad), bien la reinserción (caso de la libertad condicional). En este sentido, la Constitución española prevé que «Las penas privativas de libertad y las medidas de seguridad estarán orientadas hacia la reeducación y reinserción social...» (art. 25.2), pero, transcrito tal enunciado, no puede dejar de señalarse inmediatamente a continuación que el Tribunal Constitucional ha reiterado que de este precepto no cabe deducir un derecho fundamental, sino un principio de legislación penitenciaria.

En fin, y para terminar esta breve introducción sobre el estado de la gracia en el ordenamiento español, ha de repararse en que, siendo el Estado español actual uno de los más descentralizados de Europa, la distribución de competencias entre el Estado y las Comunidades Autónomas en nada afecta en principio a la cuestión de las instituciones de clemencia ${ }^{1}$.

\section{LA GRACIA}

El derecho de gracia no se concibe en el sistema español como una prerrogativa regaliana. La Constitución condiciona su ejercicio a que se lleve a cabo "con arreglo a la ley» [art. 62.i)]. La gracia habitual en España, de naturaleza particular, se rige por la Ley de 18 de junio de 1870, que establece las reglas para el

${ }^{1}$ Y ello porque, salvo el derecho producido por las Comunidades Autónomas en el ejercicio de la función normativa de sus competencias, y salvo algunas especificidades en derecho civil, la mayor parte del derecho común resulta competencia del Estado (derecho penal, penitenciario, mercantil, laboral, procesal —salvo excepciones—, normas sobre la propiedad industrial e intelectual, especificidades en el ámbito militar, etc.); el poder judicial es único (esto es, como tal poder no está descentralizado, aun cuando haya Tribunales Superiores de Justicia en las Comunidades Autónomas, pero están sometidos a la organización judicial general), lo mismo que el Tribunal Constitucional. De esta manera, el control de los actos realizados por las Comunidades Autónomas es un control jurisdiccional, ordinario o constitucional, apropiado a la función de tales actos. 
ejercicio del indulto. Esta Ley ha sido modificada — sin tocar lo esencial de la misma- más de un siglo después de su redacción, en 1988. La noción de gracia es definida concretamente en el artículo 4 de la misma, que también determina las personas que pueden ser beneficiadas, las categorías y los efectos de la gracia - el indulto es total si se aplica a toda la pena, y parcial si no se aplica más que a una parte-, y que prevé el procedimiento concreto a seguir y el modo de otorgar la gracia, lo que hace teóricamente posible su control, al menos en los extremos referidos ${ }^{2}$. En todo caso, sobre el fondo de la decisión (otorgamiento o rechazo de la gracia por quien detenta el poder para ello) no hay posibilidad de control, por lo menos desde que el Tribunal Constitucional haya señalado que «... el indulto, en tanto que figura del derecho de gracia, corresponde decidirlo al poder ejecutivo, concediéndolo el Rey, sin que estas decisiones sean fiscalizables sustancialmente por parte de los órganos jurisdiccionales, incluyendo este Tribunal Constitucional» $»^{3}$.

La gracia (del indulto) implica una culpabilidad judicialmente declarada, sin posibilidad de recurso. Precisamente, la Ley de 1870 dispone que el Tribunal que haya dictado la sentencia, deberá mencionar en su informe los indicios de arrepentimiento del beneficiario de la gracia, lo que, evidentemente, implica que la culpabilidad haya sido constatada ${ }^{4}$.

2 De hecho, se ha presentado un caso relativamente reciente (indulto otorgado por el Real Decreto 2392/2000, de 1 de diciembre, B.O.E. del 21), en el cual, a demanda del beneficiado (un juez condenado por prevaricación en un asunto en el que al parecer existían intereses políticos relevantes), ha tenido lugar un control judicial de su indulto, aprovechando el enfrentamiento que su otorgamiento supuso entre la Sala de lo Penal del Tribunal Supremo que le condenó, y el Gobierno que se lo otorgó. El juez beneficiado entendía que el alcance de la medida de gracia era mayor que el que entendía el órgano judicial que debía aplicarla. No puede dejar de señalarse que este caso ha permitido constatar la dificultad de un control de este tipo de medidas de gracia, tanto desde el punto de vista de los órganos que deben ejercerlo como desde el punto de vista procedimental, es decir, de las formalidades a seguir en caso de que se interese el mismo; ello, sin embargo, no ha impedido en el caso concreto precitado que se haya resuelto el caso, con numerosos recursos, de una forma muy razonable en lo que concierne a la interpretación de los instrumentos normativos del ordenamiento jurídico español.

3 ATC 360/1990, de 5 de octubre, FJ 5.

${ }^{4}$ Otra cosa es que el condenado mantenga su inocencia a pesar de la decisión declarativa de culpabilidad. El caso concreto que permanece hasta hoy y que debe ser entendido como el más próximo al tema en cuestión, es el de dos marroquíes condenados por numerosas violaciones, que ciertas pruebas han demostrado la imposibilidad de que fueran cometidas por ellos: el Ministerio Público, el Tribunal Supremo y numerosas personas, han solicitado el indulto —actualmente para el único de los que queda puesto que el otro murió en prisión - pero los interesados se han opuesto al perdón justamente porque mantienen su inocencia, no siendo la gracia — vienen a afirmaruna solución más que para los culpables. Hoy es el día en que el Gobierno no se ha pronunciado 


\section{No hay infracciones sistemáticamente excluidas de la gracia}

La Ley que regula el ejercicio del indulto comienza disponiendo en su art. 1. ${ }^{\circ}$ que «Los reos de toda clase de delitos podrán ser indultados...», estableciendo excepciones que alcanzan a características de la persona beneficiada (no haber sido condenado aún por sentencia definitiva, no estar a disposición del Tribunal sentenciador para el cumplimiento de la Sentencia o ser reincidente, con ciertas reservas en este último caso), pero no sobre la acción delictiva en sí. En consecuencia, en principio todas las infracciones son susceptibles de ser objeto de medidas de gracia 5 .

\section{Las medidas de gracia son individuales}

El sistema español actual prevé solamente medidas de gracia particulares (el indulto), mientras que prohíbe las remisiones generales de penas. Esto no impide

sobre el indulto, lo que debe ser entendido como un rechazo de la misma, pues el Real Decreto 1879/1994, de 6 de septiembre, dispone que «Los procedimientos a los que dé lugar el ejercicio del derecho de gracia habrán de ser resueltos en el plazo máximo de un año, pudiendo entenderse desestimadas las solicitudes cuando no haya recaído resolución expresa en el indicado plazo». El caso puede ser consultado en http://www.geocites.com/eva_bobrow/portada.html, con las diferentes referencias periodísticas que se señalan. Por tanto, la solicitud de gracia ha de entenderse como contradictoria con la proclamación de la inocencia. Más aún: en teoría, si le hubiere sido concedida la gracia, debería renunciar a ella quien pretenda hacer valer su inocencia, como razona el Voto Particular (que por tanto no puede ser considerado doctrina oficial) del, a la sazón, Presidente del Tribunal Constitucional a la STC 229/2003, de 18 de diciembre: «Quien acepta el perdón no puede demandar justicia. Aquél presupone la admisión tácita de una culpa previa; con la petición de justicia se niega la culpa y se exige una solución en Derecho».

5 De hecho, durante la transición política española se adoptaron diversas medidas de gracia en relación con —entro otros- delitos cometidos por terroristas, para que depusiesen las armas como contrapartida a la ausencia de consecuencias jurídicas penales por sus actividades pasadas, y con el objetivo de facilitar su reinserción. Del mismo modo, ya consolidado el régimen democrático, los miembros de la organización terroristas catalana Terra Lliure se beneficiaron de indultos específicos (cfr. B.O.E. de 19 de marzo de 1996, con dos indultos, y de 8 de agosto del mismo año, con otros catorce de componentes de la misma organización). Puede verse el supuesto de un miembro de la organización terrorista ETA — que no había cometido delitos de sangre- indultado mediante Real Decreto 1985/1996, de 23 de agosto. En los periódicos nacionales de 15 de octubre de 2004, puede leerse que el Tribunal Supremo es partidario de la gracia total de otro miembro de la misma banda terrorista — que tampoco había cometido delitos de sangre — en razón de su evidente reinserción; otro ejemplo posterior a esta fecha es el indulto habido mediante el Real Decreto 2309/2004, de 10 de diciembre (B.O.E. del 28), relativo a un caso de participación en banda armada, con delitos de daños e incendios de inspiración terrorista, pero sin crímenes de sangre.

(C) UNED. Revista de Derecho Politico

N. ${ }^{\circ} 74$, enero-abril 2009, págs. 335-351 
el otorgamiento simultáneo de la gracia particular a numerosos individuos ${ }^{6}$, porque resulta necesario entender que el carácter individual de la clemencia se determina por la singularidad de su destinatario, y no por el motivo de la misma (que no se especifica en los reales decretos de concesión). Dicho de otro modo, lo relevante es que quien detenta el poder de otorgar la gracia especifique su voluntad de otorgarla a cada uno de los que estime oportuno, con independencia de que los graciados sean numerosos y la razón de su perdón sea común.

\section{Exclusiones del beneficio del indulto}

El art. 102.3 de la Constitución española niega a los miembros del Gobierno el beneficio de la gracia en el caso de que incurran en responsabilidad penal. Nada se dice acerca de otros tipos de responsabilidades (civil, laboral, administrativa), de las que, en consecuencia, parece que deberían poder beneficiarse. Del mismo modo, si su responsabilidad penal es reconocida cuando ya no son miembros del Gobierno pero por actos cometidos cuando lo eran, resulta difícil negarles la posibilidad de la gracia, puesto que la imposibilidad del beneficio parece ligarse manifiestamente a su condición de titulares de una responsabilidad gubernamental. Respecto de los demás titulares de los poderes públicos, no previéndose jurídicamente nada, tampoco parece que puedan ser excluidos del beneficio de la gracia.

Atendiendo a la evolución de la política penal en España, ha de señalarse que no es habitual la gracia de condenados por delitos terroristas, como tampoco lo es en el caso de los autores de delitos especialmente reprochables por la comunidad, tales como la violación, el tráfico de estupefacientes a gran escala, etc. Ello se comprende fácilmente teniendo en cuenta que el encargado de otorgar la gracia en el sistema español es el ejecutivo que, pretendiendo mantenerse en el poder, no puede ponerse en una posición de disfavor frente al electorado cuando éste es particularmente sensible a ciertos delitos. Antes al contrario, el Gobierno precedente al actual cuando se redacta este cuestionario, ha endurecido las penas mediante la aprobación de leyes orgánicas específicas ${ }^{7}$.

${ }^{6}$ De hecho, en diciembre de 2000, el Gobierno otorgó 1.443 indultos: sólo la amnistía de 1977 fue superior (3.900 beneficiarios). Según opinión cuasi unánime (que nosotros suscribimos), tal cantidad de indultos fueron otorgados para intentar justificar el concedido al juez antes aludido, condenado por prevaricación.

7 Esencialmente, la Ley Orgánica 7/2003, de 30 de junio, sobre medidas de reforma en orden al cumplimiento integral y efectivo de las penas, que eleva a 40 años el límite de penas privativas de libertad, hasta ese momento fijado en 30 años. Esta ley igualmente ha endurecido las 


\section{Derecho del destinatario a rechazar la amnistía o el indulto}

Si existe o no tal derecho es cuestión debatida entre algunos de los autores que se ha pronunciado sobre el tema. A nuestro juicio debería entenderse posible. En todo caso, que conozcamos no se ha producido ningún caso de rechazo de una medida gracia otorgada ${ }^{8}$, razón por la cual no ha habido ocasión de contrastar una hipótesis tal ante la jurisdicción (ni ante los órganos judiciales ordinarios, ni menos aún ante el Tribunal Constitucional ${ }^{9}$ ).

\section{Indulto e igualdad}

En principio, la gracia no comporta problemas en la práctica desde el punto de vista del principio de igualdad, desde el momento en que su ejercicio por el poder ejecutivo es discrecional. Pero, a nuestro juicio, desde un punto de vista estrictamente teórico-constitucional, cabría fundar una reclamación sobre el principio de legalidad si aquél al que se le niega una medida de gracia demuestra estar en una situación sustancialmente igual que otro a quien se le concede,

condiciones requeridas para acceder a los permisos de salida, al tercer grado penitenciario y a la libertad condicional; la Ley Orgánica 11/2003, de 29 de septiembre, que agrava los casos de reincidencia y habitualidad, de violencia doméstica, y que sustituye la prisión de los extranjeros sin residencia legal por su expulsión; o la Ley orgánica 15/2003, de 25 de noviembre, de reforma del Código Penal, que criminaliza conductas hasta ahora no delictivas (como comportamientos en relación con la pornografía infantil, la conducción temeraria con elevadas tasas de alcohol en sangre o a velocidades excesivas, el abuso de información privilegiada en mercados bursátiles, etc.). Se trata, en unos casos, de una política condicionada por una consideración particular de las víctimas de los delitos, y en otros, de una política en concordancia con nuevas sensibilidades sociales, pero, en la línea de lo señalado en el texto principal, es difícil no ver en ella un cierto oportunismo electoral.

${ }^{8}$ Como sucedió hace relativamente poco, p. ej., en el caso de M. Ross, en Estados Unidos, quien reivindicó su derecho a ser ejecutado tras haber sido declarado culpable de la violación y muerte de cuatro mujeres y de haber confesado algunas más: fue efectivamente ejecutado en Nueva Inglaterra el 13 de mayo de 2005.

9 El Voto Particular del Presidente del Tribunal Constitucional antes aludido (a la STC 229/2003), es contradictoriamente revelador, porque afirma que «Es cierto que la gracia no es repudiable por quien la recibe sin haberla pedido, pero la pretensión de interesar una respuesta jurisdiccional para lo que ha quedado solventado tras la gracia sólo puede prosperar si, con fundamento en el derecho a la jurisdicción, se impugna la propia concesión graciosa. En otro caso sólo se generarían consecuencias perturbadoras para el Ordenamiento y, si se quiere, para los intereses del afectado, pues basta pensar en el supuesto de un pronunciamiento jurisdiccional estimatorio que llevara aparejado un nuevo enjuiciamiento de la causa que fue indultada, respecto del cual ya no produciría efectos, evidentemente, la primera gracia». 
pues de permitir tal desigualdad se estaría quebrantando el principio de interdicción de arbitrariedad constitucionalizado en el artículo 9.3 CE, pues una cosa es la discrecionalidad y otra la arbitrariedad; parece, no obstante, una situación que es bastante difícil que se dé en la práctica.

\section{Relación con los principios de necesidad de las penas, de seguridad jurídica $y$ de protección del orden público}

En España no hay períodos en que tradicionalmente se haga uso de la gracia (anualmente, después de las elecciones, etc.), pero hay un "gota a gota» a lo largo del año de indultos que aparecen en el Boletín Oficial del Estado, sin regularidad determinada ni especiales razones institucionales.

La relativa frecuencia de la gracia y la fórmula sucinta utilizada para publicar su otorgamiento en el Boletín Oficial del Estado (que no permite conocer el motivo por el que el Gobierno la concede), no son consideradas como un exceso de poder en detrimento de la seguridad jurídica y de la protección del orden público. En efecto, la Constitución, que garantiza la específicamente el principio de la seguridad jurídica (art. 9.3) y que hace alusión a la noción de "orden público» (art. 16.3 y art. 21.2), prevé también [arts. 62.i), 87.3 y 102.3] la existencia del poder de gracia. La cuestión adquiere un alcance mayor en relación con el principio de necesidad de las penas, pues si éste es entendido como la necesidad de su cumplimiento, el Tribunal Constitucional ha considerado ${ }^{10}$ que no hay un derecho (fundamental) al ejercicio del ius puniendi del Estado como tal. Por tanto, a fortiori, se puede deducir fácilmente que, una vez ejercido el ius puniendi, no se atenta contra el principio del cumplimiento de las penas si, por una razón $\mathrm{u}$ otra, quien ejerce la facultad de indultar considera oportuno suprimir toda o parte de la pena.

Dicho esto, y desde un punto de vista teórico, es evidente que el ejercicio de la gracia erosiona el derecho a una tutela judicial efectiva, pues parte esencial de esa efectividad consiste en ejecutar las penas impuestas una vez juzgados los casos: en todo caso, tal ejecución podría ser parcial o totalmente alterada por la aplicación de la clemencia de existir una sólida razón que así lo aconsejase, pero, a fecha de hoy, los Reales Decretos que la otorgan no explicitan su justificación o motivación.

${ }^{10}$ No a propósito de la gracia, sino a propósito de la pretensión de sujetos de que se persigan delitos de los que afirman haber sido víctimas. 
Efectos del indulto sobre el concurso de delitos y sobre los antecedentes penales

La gracia del indulto se proyecta sobre las penas concretas, derivadas de acciones ilícitas (y no, como en el caso de la amnistía, sobre la acción ilícita como tal). Todo lo que no es pena, no resulta afectado por el indulto (p. ej., la remisión de la pena no afecta a los antecedentes penales).

Si las penas no han comenzado a ser cumplidas, la gracia será total, pero no tiene efectos retroactivos, salvo en el caso de contenidos pecuniarios de aquéllas. Estos son los únicos contenidos de los que la Ley de 1870 prevé la posibilidad de proceder a su restitución si el Decreto de concesión así lo dispone expresamente. En todo caso, la gracia no puede tener efectos ni sobre los gastos del proceso ni sobre las responsabilidades civiles, y no comprenderá el beneficio sobre la inhabilitación para cargo público, la imposibilidad del ejercicio de derechos políticos y la vigilancia de la autoridad, a no ser que resulten especificados como objeto del beneficio en el Decreto que lo concede.

Si la pena o penas han comenzado a ser cumplidas, la gracia concedida será parcial, pudiendo consistir bien en la remisión de todo o de parte de lo que reste por cumplir, bien en la conmutación por otras menos graves. Por otro lado, las penas accesorias pueden ser objeto de beneficio de forma independiente de las principales, siendo también posible, aunque menos probable, lo inverso, salvo que unas y otras sean inseparables en razón de su naturaleza y de sus efectos.

Se puede deducir de lo que se acaba de exponer (que viene a ser un resumen literal de la Ley reguladora de la gracia del indulto en España) que nada impide aplicar la gracia a distintas penas impuestas a una persona, aun cuando traigan causa de diferentes ilícitos, pues la ley en cuestión prevé la remisión de todas o de una parte de las penas, o de una parte de unas o de las otras.

\section{Indulto y separación de poderes}

En el sistema español no se cuestiona el principio de separación de poderes con motivo del ejercicio del poder de gracia, porque es indiscutible que la única forma de gracia que se practica después de la Constitución de 1978 — la gracia individual- corresponde siempre al Gobierno, bien que ex lege, sin que ello presente mayores problemas.

\section{Instituciones de clemencia y referéndum e iniciativa popular}

Como se ha dicho, el art. 87.3 de la Constitución española estipula que no se ejercerá la iniciativa popular «... en lo relativo a la prerrogativa de gracia». Esto

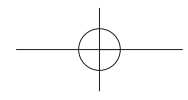


excluye que 500.000 personas (número establecido por el art. 87.1 de la Constitución para poder presentar iniciativas de este género) puedan dirigir al legislador proposiciones de textos para regular la gracia de una manera determinada.

En lo referido al referéndum, disponiendo el art. 92.1 de la Constitución española que "Las decisiones políticas de especial trascendencia...» puedan ser sometidas a referéndum consultivo, parece difícil concebir que tal instrumento pueda ser empleado para la regulación de las instituciones de clemencia. La posibilidad de someter a referéndum la concesión por el Gobierno de la gracia a uno o a varios individuos, requiere considerar tal concesión como «una decisión política de especial trascendencia», pues a este requisito somete la Constitución la posibilidad de convocar referéndums. Es evidente que tal requisito ha sido pensado para otros supuestos ${ }^{11}$. En todo caso, el constituyente español optó claramente por una democracia representativa, en detrimento de una democracia directa, y es evidente que la Constitución contempla restrictivamente los instrumentos que son propios de esta última. En consecuencia, la consulta popular de una decisión de conceder el beneficio de la gracia a quienes han sido juzgados y condenados conforme a la ley, aparece no sólo como una hipótesis improbable, sino disconforme con el espíritu de la Constitución. Por lo demás, el ejecutivo (a cuyo Presidente corresponde en exclusiva proponer un referéndum de este tipo: art. 92.2 CE), puede otorgar la gracia cuado lo estime oportuno, afrontando así el riesgo o la ventaja (políticos) que una medida tal entraña en caso.

A cambio, la posibilidad de una solicitud de gracia formulada por particulares en relación a un condenado determinado (o a un grupo de ellos), está prevista por la citada Ley de 1870, reguladora del ejercicio de la gracia del indulto, que dispone que no solamente los propios condenados o sus familiares puedan solicitar el beneficio, sino también «cualquier persona en su nombre, sin necesidad de poder escrito que acredite su representación» (art. 19) ${ }^{12}$.

\section{Medidas de clemencia y derecho penal internacional}

La Ley Orgánica del Poder Judicial (LOPJ), impide a los órganos judiciales conocer de delitos cometidos, tanto en el interior como en el exterior del terri-

\footnotetext{
${ }^{11}$ Hasta la fecha, bajo el régimen constitucional en vigor sólo han tenido lugar dos referéndums: en relación con la adhesión a la OTAN, en 1986, y en relación con el proyecto de Constitución Europea, en febrero de 2005.

${ }^{12}$ De hecho, en algunas ocasiones se han elevado miles de solicitudes de gracia en favor de altos responsables civiles o militares condenados por razones diversas en relación con el ejercicio ilegal de sus funciones.
} 
torio nacional español, y tanto por españoles como por extranjero que hubiesen adquirido la nacionalidad española con posterioridad a la comisión del hecho, cuando el delincuente haya sido indultado en el extranjero respecto de sus infracciones (art. 23.2). Esta disposición concierne incluso a los casos de infracciones conocidas como crímenes contra la humanidad (así, el genocidio, el terrorismo, la prostitución y la corrupción de menores, el tráfico de drogas «[y] cualquier otro que, según los tratados o convenios internacionales, deba ser perseguido en España», según el art. 23.3 LOPJ), aunque sus autores no sean nacionales, sin que se excluya de la aludida imposibilidad de conocimiento en el supuesto de que haya habido indulto ${ }^{13}$.

\section{LA AMNISTÍA}

Como antes se ha indicado, la interdicción constitucional del indulto general, conjugada con la ausencia de toda ley de amnistía bajo la vigencia de la Constitución de 1978, conduce a dudar de la 'practicabilidad', por así expresarlo, de esta institución jurídica en cuanto tal en el sistema español. A nuestro entender, lo anterior no significa sin embargo que la misma sea imposible: sus efectos se han visto en el ordenamiento, siquiera sea por las consecuencias de la última Ley de amnistía publicada en España (Ley 46/1977, de 15 de octubre, B.O.E. del 17), durante la transición política del régimen franquista a la democracia e, incluso, como se ha anunciado y se dirá a continuación, puede encontrarse alguna de sus formas en la actualidad.

13 Un caso particular, bien que no tenga relación alguna con la cuestión de la gracia, ha surgido con motivo de la reciente creación de la Corte Penal Internacional y la firma por España del Tratado correspondiente. La Constitución española establece que «La persona del Rey es inviolable y no está sujeta a responsabilidad» (art. 56.3 CE), lo que ha suscitado la idea en algunos juristas de la necesidad de reformar la Constitución para adaptarla a la Convención o bien de incluir en ésta una cláusula de salvaguardia referida a la persona del Rey con el fin de que éste quede a salvo de un eventual encausamiento por el Tribunal Penal Internacional. La mayoría de la doctrina, y nosotros con ella, estima sin embargo, que no es necesario lo anterior, pues el citado art. 56.3 CE dispone que los actos del Rey «... estarán siempre refrendados..., careciendo de validez sin dicho refrendo, salvo lo dispuesto en el artículo 65.2» (precepto este último que hace referencia únicamente a la libre nominación por el Rey de los miembros civiles y militares de la Casa Real), lo que hace evidente que la falta de responsabilidad de la persona del Jefe del Estado español (en lo que interesa a la Convención de la que surge la Corte Penal Internacional) proviene del hecho de que, para realizar actos válidos (no privados), los mismos deben ser refrendados. 


\section{La amnistía politica o de crimenes políticos}

Las medidas de clemencia decretadas durante la transición política como amnistías no presentaron problemas, lo que se explica sin ninguna duda por el momento tan particular y por las circunstancias en las que las mismas tuvieron lugar, así como por su propio objetivo: con ellas se pretendía, evidentemente, romper con el pasado y hacer posible el comienzo de un nuevo régimen, basado en el consenso más amplio posible. Cuando se escriben estas líneas, hay un debate importante sobre las posibles medidas en favor de los encarcelados de la banda terrorista ETA, en relación con hipotéticas negociaciones del ejecutivo con tal organización con el objetivo de que ésta deponga las armas.

Existe una amnistía fuera del ámbito penal (sanciones administrativas, disciplinarias,...)

El Reglamento del régimen disciplinario de los funcionarios de la Administración del Estado, aprobado por Real Decreto 33/1986, de 10 de enero (posterior, por tanto, a la Constitución de 1978), dispone a la fecha en que se redacta este cuestionario, que: «La responsabilidad disciplinaria de tales funcionarios desaparece por... [entre otras razones] el indulto y la amnistía» (art. 19.1), especificando que «La amplitud y los efectos de las medidas de gracia sobre sanciones disciplinarias se regularán por las disposiciones que las concedan» (art. 22).

Por otro lado, la vigente Ley 58/2003, de 17 de diciembre, General Tributaria, reserva a la ley "la remisión de deudas y sanciones fiscales...» [art. 8.k)], especificando que "las deudas fiscales pueden resultar solamente objeto de condonación en virtud de la ley, según el montante y en las condiciones requeridas que aparezcan determinadas en dicha ley» (art. 75), de donde se puede inferir que en el sistema español cabe la «amnistía fiscal» en el sentido más estricto, es decir, por deseo de la ley, como corresponde a la figura de la amnistía, sin que haya ninguna otra forma prevista de beneficio sobre tal objeto ${ }^{14}$.

Finalmente, en el ámbito militar, el art. 30 del Código Penal Militar determina que los militares de profesión que hayan sido condenados a la pérdida de

${ }^{14}$ En todo caso, es posible, en la práctica, acordar una amnistía simulada, como — según la Organización de Inspectores de Finanzas del Estado- es la que está teniendo lugar en el momento en que se escriben estas líneas, con las conocidas como SICAV (Sociedades de capital variable) utilizadas por las grandes fortunas para negociar su patrimonio: el Congreso de los Diputados ha instaurado la posibilidad de que paguen un impuesto del 1\% (cfr. el diario El País, 1 de julio de 2005). 
su empleo militar, pérdida que provoca su licenciamiento de las Fuerzas Armadas, no pueden ser rehabilitados «sino en virtud de ley», lo que, en rigor, parece constituir una amnistía clara (individual si afecta a una sola persona, o general si afecta a numerosas personas en relación a una misma causa).

\section{La amnistía y los derechos de terceros}

La última amnistía promulgada en España (como se ha dicho, por Ley 46/1977, de 15 de octubre) durante la transición política, ha tenido efectos cara a terceros, específicamente en el ámbito del derecho laboral. La misma previó un derecho de reparación, al disponer la privación de efectos de las consecuencias negativas (como despidos, sanciones, etc.) derivadas de actos efectuados con intención política o del ejercicio de actuaciones de naturaleza laboral o sindical que supusieran el desconocimiento de derechos reconocidos por normas o convenciones internacionales en vigor, debiendo serles restituidos a los concernidos todos los derechos de los que gozarían a la fecha de la Ley de no haber sobrevenido tales consecuencias negativas. En consecuencia, quienes solicitaron ser reintegrados en sus empresas y acudieron a jueces y tribunales en aplicación de dicha ley, hubieron de ser readmitidos o indemnizados. Algunas empresas recurrieron estas decisiones judiciales, alegando que los despidos habían sido efectuados de conformidad con la legislación en vigor a la sazón, sin que lograsen que su pretensión prosperase ${ }^{15}$.

En el mismo sentido, las Administraciones públicas también han acordado reparaciones sobre la base de la citada amnistía. Así, la Ley 4/1990, de 30 de diciembre, de Presupuestos del Estado para 1990, incluyó, en su D. A. 18. ${ }^{a}$, el reconocimiento de «indemnizaciones a favor de aquellos que sufrieron prisión como consecuencia de los supuestos aludidos en la Ley 46/1977, de 15 de octubre»; así también, las leyes de la Comunidad Autónoma vasca 11/1983 y 1/1985, acordaron ayudas económicas a aquellos que trabajaron en la Administración autónoma del País Vasco entre octubre de 1936 y enero de 1978.

\section{PRESCRIPCIÓN}

En lo concerniente a la prescripción, no se puede considerar que en el Derecho español exista un «derecho al olvido» como una vertiente del derecho a la

${ }^{15}$ Cfr. al respecto ATC 351/1982, de 17 de noviembre, y AATC 88 y 89/1983, de 2 marzo. 
clemencia, sino más bien, diríamos nosotros, un derecho a la estricta aplicación de la ley penal en relación con el acto ilícito cometido por el sujeto juzgado en el tiempo que determina aquélla. Así entendido, lo que se designa en el cuestionario como «derecho al olvido» no sería sino el contrapunto necesario del principio de seguridad jurídica penal; este principio impone un límite temporal a la efectividad del ius puniendi del Estado, puesto que no se podría soportar, como norma habitual, una pendencia eterna del ejercicio del mismo en relación con cualquier delito cometido cualquiera que hubiera sido el momento pasado; excepciones a la norma habitual antedicha pueden darse, y se dan, con delitos tan extremadamente odiosos para la comunidad, en razón tanto de su deleznable significado moral como de las obligaciones internacionales adquiridas al respecto, de donde deriva para ellos un régimen especial de imprescriptibilidad, según se concreta a continuación.

\section{Prescripción y delitos imprescriptibles}

El art. 131.4 del Código Penal, en la revisión resultante de la L. O. 15/2003, de 25 de noviembre, dispone que "Los delitos de lesa humanidad y de genocidio y los delitos contra las personas y bienes protegidos en caso de conflicto armado, no prescribirán en ningún caso» ${ }^{16}$.

Cuestión distinta es si tal imprescriptibilidad comporta también la insusceptibilidad de que tales delitos puedan ser objeto del beneficio de la gracia. Si se dejan a un lado los argumentos de la inconveniencia o de la escasa lógica que - a priori al menos - comporta permitir la aplicación de la gracia a delitos cuya gravedad ha llevado al representante cualificado de la comunidad política (en no pocos casos, siguiendo lo acordado por la comunidad internacional más próxima jurídico-culturalmente) a considerarlos imprescriptibles, lo cierto es que la Ley de 1870, reguladora de la gracia del indulto, comienza determinando en su art. 1, según se ha transcrito ya antes, que «Los reos de toda clase de delitos podrán ser indultados...»; literalmente ello incluye a los reos de delitos imprescriptibles, lo que guarda coherencia con el citado art. 23 LOPJ, en cuanto impide conocer a los jueces españoles de los hechos cometidos por español previstos en nuestras leyes penales como delitos, si ha sido indultado en el extranjero.

${ }^{16} \mathrm{Y}$ el art. 134.3 CP dispone que tampoco prescribirán las penas impuestas por tales delitos. Los delitos de genocidio son definidos en el art. 607 CP, los de lesa humanidad en el art. 607 bis CP, las personas protegidas en caso de conflicto son determinadas en los arts. 608 et ss. CP y los bienes en el art. $613 \mathrm{CP}$ (los arts. 607 bis, 608 y 613 son preceptos nuevos introducidos por la mencionada L.O. 15/2003). 
Respecto de las prescripciones establecidas

Como se ha comenzado diciendo, la Constitución española no contiene alusión directa o indirecta a la prescripción, ni penal ni de otros tipos. No obstante, el respeto de las prescripciones legalmente establecidas debe ser comprendido bien como una vertiente del derecho a la tutela judicial efectiva, garantizado por el art. 24.1 CE, de modo que su desconocimiento por parte de los poderes públicos implicaría una decisión no fundada sobre el derecho en vigor y, como consecuencia, no conforme con la Constitución; bien acaso, incluso, como vertiente del principio de legalidad penal, que impediría igualmente perseguir un delito tras el transcurso del plazo que la propia ley determina para declararlo prescrito.

\section{Evolución de la duración de la prescripción}

Como se ha dicho antes, en razón de la reforma del Código Penal por L. O. 15/2003, de 25 de noviembre, ciertos delitos han sido añadidos al único —el de genocidio-, y a su pena, que hasta esa fecha se determinaba como imprescriptible, de suerte que los delitos de lesa humanidad y de genocidio y los delitos contra las personas y bienes protegidos en caso de conflicto armado, han devenido a partir de esa fecha también imprescriptibles (arts. 131.4 y 133.2 C.P.).

La misma Ley Orgánica ha introducido como novedad que las penas superiores a 20 años de prisión no prescriben hasta los 30 años (antes, las penas superiores a 15 años prescribían al cabo de 25 años).

Title

\section{THE MERCY LINKED BY THE LAW}

\section{Summary}

I. MEASURES OF MERCY AND CONSTITUTION. II. THE PARDON. III. THE AMNESTY. IV. PRESCRIPTION.

\section{Resumen}

La aportación consiste en la exposición extractada del régimen legal de las instituciones típicas de la gracia (amnistía y gracia particular o indulto) en el ordenamiento jurídico español, a la que se añade otra institución que, aunque no obedece a la misma naturaleza de aquéllas, está sin duda muy próxima a ellas, como es el caso de la prescripción. 
Respecto del indulto no se plantean especiales problemas en el sistema español acerca de su prohibición ex Constitutione en el caso del indulto general, ni, en el caso del indulto individual, en relación con su existencia — en este caso garantizada ex Constitutione también- y su ejercicio; respecto de éste, no obstante, sí se da cuenta de singularidades relevantes acerca del mismo (posibilidad o no de renuncia al mismo por el beneficiado, susceptibilidad o no de de su control formal y material, etc.). Respecto de la prescripción, presente en el ordenamiento español en este caso ex lege, no ex Constitutione, tampoco parecen plantearse especiales problemas desde la perspectiva constitucional, entendida tal institución como una exigencia puramente práctica, pues su ausencia haría insoportable para el sistema una pendencia eterna del ejercicio del ius puniendi estatal; de esta idea, no obstante, se excepcionan crímenes con un significado especialmente odioso para la comunidad nacional e internacional. La posibilidad de la amnistía en el ordenamiento español, sin embargo, es más discutida por la doctrina, que deriva su imposibilidad de la prohibición constitucional del indulto general: el autor mantiene la dificultad de concebirla como vedada para el legislador dada la libertad de configuración de éste y la inexistencia de prohibición constitucional expresa (contra lo que sucede en el caso del indulto general), y dada también la distinta naturaleza de ambas figuras, la gracia del indulto y la amnistía. La explicación forma parte de una amplia investigación sobre tales instituciones en el derecho comparado, tanto desde la perspectiva del derecho internacional como constitucional-penal, investigación llevada a cabo en Francia, donde ha aparecido publicada, y de la que la presente exposición constituye la aportación española, si bien con algunas precisiones idiomáticas y algún añadido que el autor considera relevantes.

\begin{abstract}
The contribution consists of the exhibition summarized of the legal system of the typical institutions of the mercy (amnesty and pardon) in the juridical Spanish system, to that is added another institution that, though it does not the same nature of those, is undoubtedly next them: periods of prescription. In relation of the pardon, special problems do not appear in the Spanish system: if the general pardon is prohibited ex Constitutione, the individual pardon is expressly provides by the Constitution also; relate to this one, nevertheless, the contribution indicates relevant singularities (possibility or not of resignation to the same one for the beneficiary, susceptibility or not of his formal and basic control, etc.). To concern of the period of
\end{abstract}


prescription, present in the Spanish juridical system in this case ex lege, and not ex Constitutione, they do not also seem to raise special problems from the constitutional perspective, understood the same one as a purely practical exigency, because there would turn out to be simply unbearable for the system his absence from which it would derive an eternal pendency of the exercise of the ius puniendi of the state; there are exceptions, when the crimes are so extremely moral hateful for the national and international community that they are considered without any period of prescription. The possibility of the amnesty in the Spanish system, nevertheless, is more discussed by the doctrine, which derives his impossibility of the constitutional prohibition of the general pardon: in the article, nevertheless, there is kept the difficulty of conceiving like forbidden for the legislator because of the freedom of configuration of this one and the nonexistence of constitutional prohibition expresses (unlike it happens in case of the general pardon), and because of the different nature of both figures, amnesty and pardon.

This contribution forms a part of a wide research work in comparative law on the alluded institutions (mercy and prescription), so much from the perspective of the international law as the constitutional law; research carried out in France, where it has turned out to be published, and of the one that the present exhibition constitutes the Spanish contribution, though with some idiomatic precisions in contrast with the publication and some addition that the author considers to be relevant.

Palabras clave

Medidas de clemencia y Constitución. Gracia. Amnistía.

Key words

Measures of mercy and Constitution. The pardon. The amnesty.

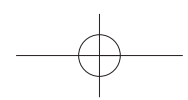

